\title{
Fire Safety Engineering - Numerical Assessment of the Mechanical Behaviour of a Steel Structure Exposed to Natural Fire
}

\author{
Dhionis DHIMA \\ Daniel JOYEUX \\ Joël KRUPPA
}

CTICM - Research and Fire Engineering Section

Domaine de Saint Paul

BP 64

78470 SAINT-REMY-LES-CHEVREUSE

FRANCE

\begin{abstract}
The fire parts of Eurocode 1 (actions) and 3 (steel structures) allow the use of advanced analytical and numerical calculation methods for fire engineering design.

This paper reports on an application of the natural fire safety concept applied to a new steel framed building. Different probable natural fires scenarios have been studied and in each case, a two zone model has been used in order to determine the fire temperature within the building for each scenario. For the most dangerous fire scenarios, the heating of different elements as well as the mechanical behaviour of the steel structure has been determined by finite element programs. Finally, for parts of the structure where the fire stability is not verified, the critical temperature has been obtained in order to determine the insulation requirements.
\end{abstract}

KEYWORDS : Natural fire, heat transfer, mechanical behaviour, Eurocode, steel column, truss.

\section{INTRODUCTION}

For a new steel framed building the behaviour in fire of the principal elements has been studied using the natural fire safety concept. According to the French regulations [1], this type of building is required to have a fire stability of 90 minutes under the standard ISO fire. 
The fire can take place on two main levels, the waiting hall and the fourth floor. Only the case with the fire in the waiting hall has been studied here. Part of the waiting hall is subdivided in three levels (the main level 1 and 2 intermediate levels). Since the volume of waiting hall is very large ( $14 \mathrm{~m}$ height) with very few combustible material, the 90 minutes requirement is very onerous. In this case it is worth to refer to fire engineering approach in order to make a more realistic assessment of the fire severity as well as of the mechanical behaviour of the loaded structure.

This paper reports on the various stages followed in using advanced calculation models for assessing the fire behaviour of this building. A two-zone model (CFAST) has been used in order to study the fire development. The temperature field within the loadbearing elements was obtained with a finite element software and the assessment of deformation (including collapse) of the structure was made by using a 3-D finite element program.

The use of the advanced calculation method for mechanical behaviour is particularly useful for the steel truss since only its lower chord members are exposed to a fire in the waiting hall.

\section{DESCRIPTION OF THE BUILDING AND THE STUDIED ELEMENTS}

The dimensions of this building are :

- length : $115 \mathrm{~m}$

- width : $81 \mathrm{~m}$

- height : $20 \mathrm{~m}$

In this building there are two main levels :

- Main level 1, or the waiting hall has the following dimensions : floor about $6000 \mathrm{~m}^{2}$ and height $14 \mathrm{~m}$. Inside this hall there are three independent blocks, see figure 1 . The floor of the first block belong to the waiting hall as well. The blocks of intermediate levels 2 and 3 are used as conference rooms and offices. These blocks have 90 minutes ISO-fire rating walls.

- Main level 4 has a surface area of $9000 \mathrm{~m}^{2}$ divided into 9 fire compartments. The fourth level floor is supported on a steel truss system.

The concrete floor separating the waiting hall from the fourth level, satisfies REI criteria (loadbearing capacity $\mathrm{R}$, integrity $\mathrm{E}$ and thermal insulation I) for 90 minutes. The lower members of the principal and secondary trusses are below the floor, in the volume of level 1 , see figure 2 .

The steel structure has 6 principal trusses and 18 secondary trusses. The secondary trusses are perpendicular to and supported by the principal trusses. For each type of truss only the more critically loaded are presented in this study. The Figure 12 represents the principal truss and the supporting columns together with the main dimensions. The Figure 13 provides details of the secondary truss and its main dimensions.

The section dimensions of the heated steel elements studied are :

- type 1: the lower members of the trusses, HEA 550 sections, with three faces exposed to fire 
- type 2: internal rectangular hollow section columns 500x500 with plate thickness 12 , 15 and $18 \mathrm{~mm}$ and four faces exposed to fire

- type 3 : facade rectangular hollow section columns 360x360 with plate thickness $12 \mathrm{~mm}$ and two faces exposed to fire

- type 4: facade welded plate girder section columns $500 \times 15-500 \times 8-500 \times 15$, with one face exposed to fire

- type 5: ceiling joists, welded plate girder section $350 \times 60-1000 \times 10-350 \times 60$, with three faces exposed to fire

The height of all columns is $14 \mathrm{~m}$ and the span of the ceiling joists is $16.85 \mathrm{~m}$.

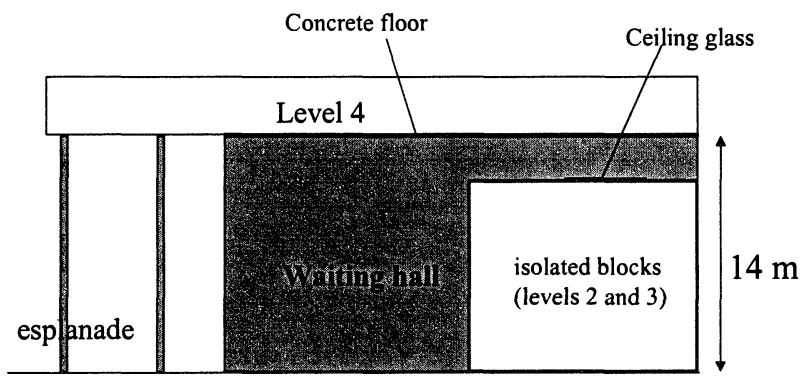

FIGURE 1 : Section through the building

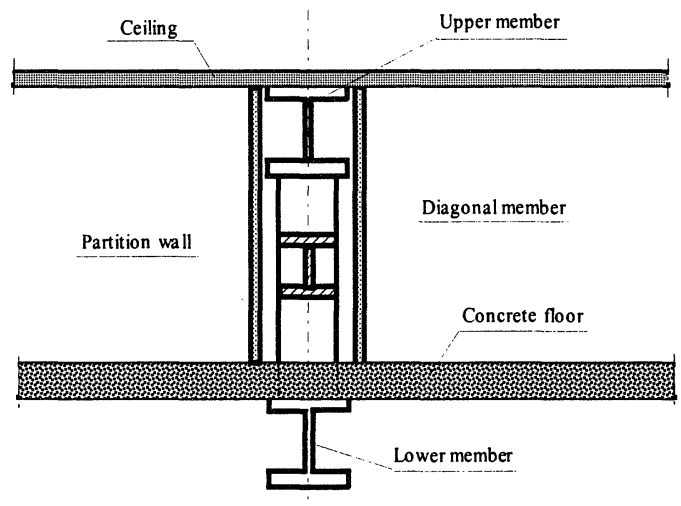

FIGURE 2 : Section of the floor at truss height

\section{FIRE SCENARIOS AND HEATING OF THE STEEL STRUCTURE}

In order to study the mechanical behaviour of the structure a knowledge of the heating of the steel members is required. The large volume of the waiting hall contains a small fire load. The compartmentation of the levels 2 and 3 of this volume generates some well-defined natural fire scenarios. For this configuration, a natural fire safety concept has been developed. The 
principal steel structure of the building can be affected if the fire breaks out in one of the rooms of these intermediate levels, or on the floor of the waiting hall. In order to determine the thermal actions on the steel structure, three phases have been defined :

- fire scenarios definition

- fire development assessment

- calculations of heat transfer to structural elements

\subsection{Fire Scenarios}

Different fire scenarios have been defined according to the possible fire source that may induce heat transfer to the steel structure.

The different sources come from the 3 blocs of the main level 1 :

- waiting hall level 1

- conference room at intermediate level 2

- offices on intermediate level 3

From these 3 fire sources, 7 fire scenarios have been defined [2]. Only the 2 most important scenarios are presented in this paper :

a- a generalised fire in a conference room with the glass ceiling broken

b- localised fire in the waiting hall

\subsubsection{Fire scenario "a"}

An assessment of the combustible mass of furniture in the conference room has been done and a wood equivalent fire load is determined. The density of this fire load was $68 \mathrm{~kg}$ of wood $/ \mathrm{m}^{2}$ of floor. It is supposed that the glass ceiling of this room has been broken at the beginning of the fire. In these conditions the hot gases exhausting from the room move towards the ceiling of the waiting hall and heat up the steel elements of the trusses and the columns, see figure 3.

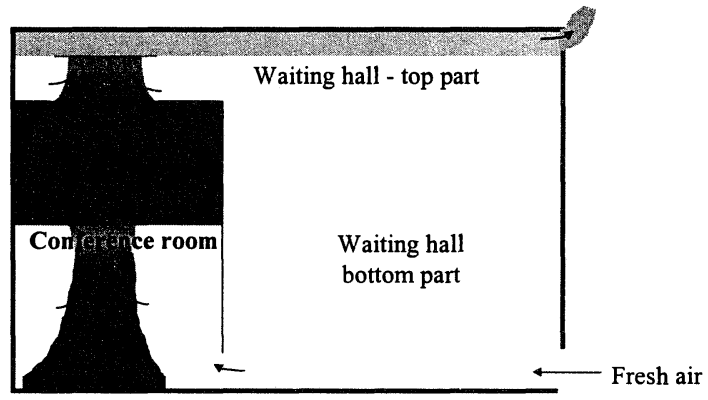

FIGURE 3 : Configuration of fire scenario "a"

With the fire load, the dimensions of the room and the openings, the temperature-time curves of the hot layer gases in conference room (used to determine temperature of elements located above the glass) and in the waiting hall (used to determine temperature of elements located far away the plume) calculated using the code CFAST and shown in figure 4.2. 


\subsubsection{Fire scenario " $b$ "}

For this scenario two localised fires, in the waiting hall, are studied :

- $1500 \mathrm{~kg}$ of wood as an equivalent fire load on $15 \mathrm{~m}^{2}$ (reception zone)

- $300 \mathrm{~kg}$ of wood as an equivalent fire load on $5 \mathrm{~m}^{2}$ (waiting area)

In order to calculated the fire temperature in different heights of the plume, the empirical equation of Heskestad has been used considering a fire duration of 30 minutes to evaluate the rate of heat release :

$$
\mathrm{T}(\mathrm{z})=25 \frac{\mathrm{Q}_{\mathrm{c}}^{2 / 3}}{\left(\mathrm{z}-\mathrm{z}_{0}\right)^{5 / 3}}+20
$$

Where :

$$
\begin{aligned}
& \mathrm{z}_{0}: \text { is the virtual origin given by }: \mathrm{z}_{0}=-1.02 \mathrm{D}+0.083 \mathrm{Q}^{2 / 5} \\
& \mathrm{D}: \text { is the seat fire diameter }(\mathrm{m}) \\
& \mathrm{z}: \text { height in the plume }(\mathrm{m}) \\
& \mathrm{Q}: \text { heat release }(\mathrm{kW}) \\
& \left.\mathrm{Q}_{\mathrm{c}}: \text { convective heat release }(\mathrm{kW}) \text { (equal to } 0.8 \mathrm{Q}\right)
\end{aligned}
$$

The figures 4 and 5 give the evolution of the temperature with the height for both scenarios.

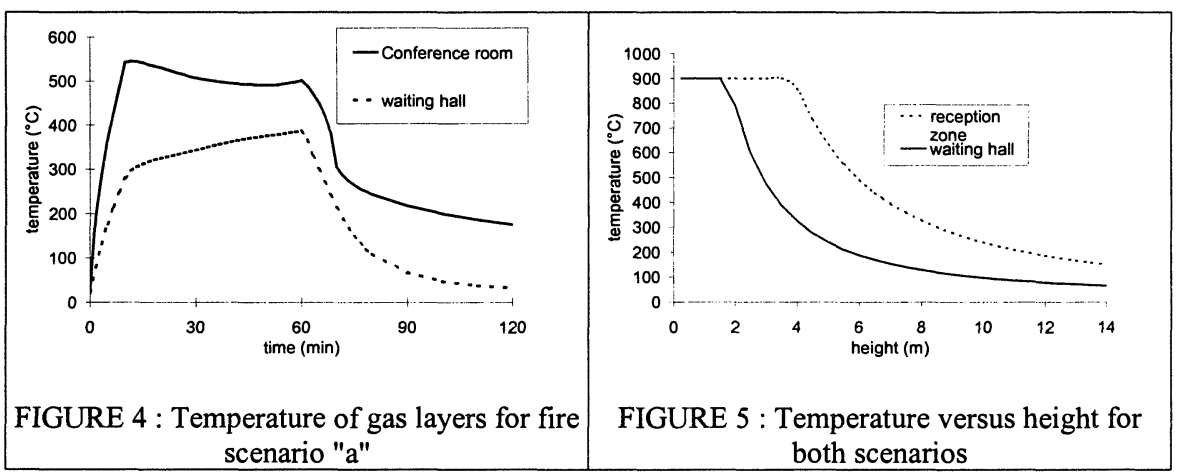

\subsection{Heating of the Steel Structure}

According to the two fire scenarios presented above the heating of different elements of the principal steel structure has been determined. The temperatures attached by the lower member of the principal beams and the secondary trusses as well as the facade columns have been determined using a 2D finite element program (TASEF) [3]. On the other hand for the calculation of the heating temperature of the columns inside the building the heating method proposed by Eurocode 3 - part 1.2 [4] has been used. The internal columns are engulfed in flame and the section temperature is uniform. The thermal properties of the steel elements used are those given by Eurocode 3 - part 1.2. 
For the five cross section types, see (2), the following heating time-temperature curves have been determined.

\section{- Section type 1 - Profile HEA 550}

This section is located above the horizontal opening of the conference room, the thermal action is given by the curve "conference room temperature" of figure 4 . The figure 6 shows the three heating time-temperature curves, of flanges and web.

For the columns, the heating of each section has been calculated for 8 profiles along the height of the column at increments of $2 \mathrm{~m}$ above the floor. The thermal action is given according to scenario $b$ by the "Reception zone" temperature curve in figure 5 . This temperature as function of height is applied during a plateau of 30 minutes, using a temperature rise of 12 minutes from $20^{\circ} \mathrm{C}$ and a temperature decrease of 12 minutes.

\section{- Section type 2 - Internal rectangular hollow section column 500x500 with plate} thickness $15 \mathrm{~mm}$

For this column which is engulfed in flames the temperature across the section is uniform. The figure 7 shows heating time-temperature curves for 8 profiles.

\section{- Section type 3 - Facade rectangular hollow section columns $360 \times 360$ with plate thickness $12 \mathrm{~mm}$}

For this particular column that is partially engulfed in flames, five heating time-temperature curves have been calculated. The figure 8 shows the temperature of the most heated section and figure 9 shows the temperature of the less heated section. The figure 10 shows how these temperatures have been assigned to the cross section of this column. The highest temperatures are calculated for T5 and T4 (exposed to fire) and the lowest temperatures for T2 and T3 (unexposed to fire). The temperature $\mathrm{T} 1$ is representative of the junction between exposed and unexposed sides.

\section{- Section type 4-Facade welded plate girder column 500x15-500x8-500x15}

For this column that is also partially engulfed in flames, three heating time-temperature curves have been calculated. For the most exposed flange, the maximum temperature at the floor level was $650{ }^{\circ} \mathrm{C}$ and minimum temperature at the ceiling level was $65^{\circ} \mathrm{C}$.

\section{- Section type 5 : - Ceiling joist}

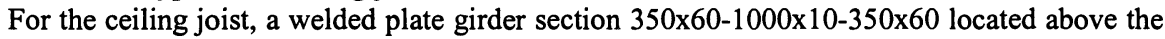
hottest zone ("conference room temperature" of figure 4) of scenario a, the time-temperature curves of the section with the highest temperature are shown in figure 11. 


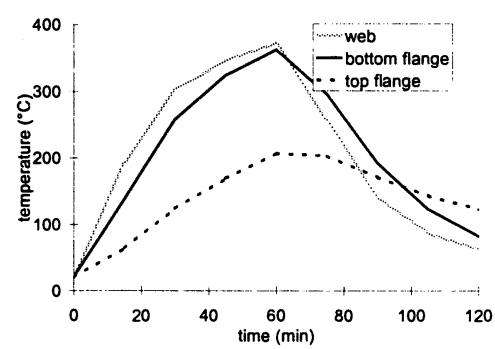

FIGURE 6 : Temperature of HEA 550 section

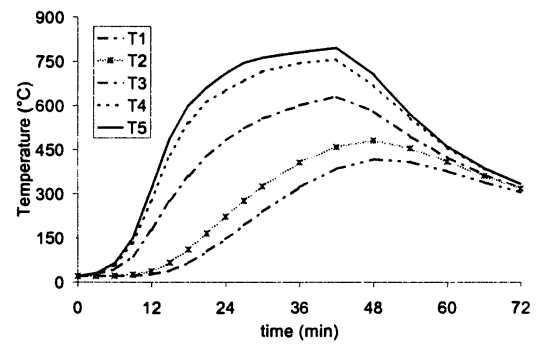

FIGURE 8 : Temperature of the column section type 3 at $0 \mathrm{~m}$

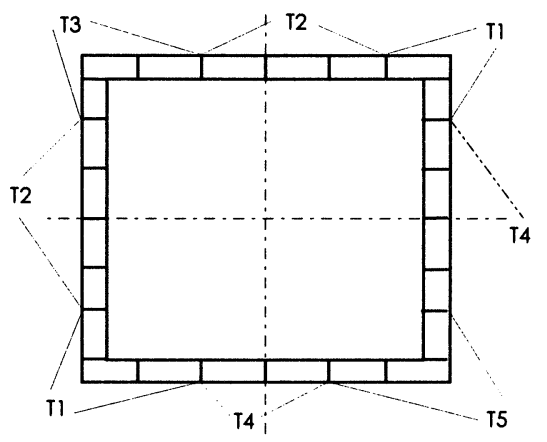

FIGURE 10 : Attribution of calculated temperatures within the rectangular hollow section $(360 \times 360 \times 12)$

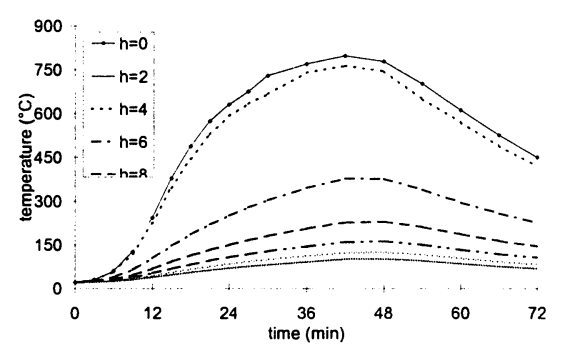

FIGURE 7 : Temperature of column -section type 2

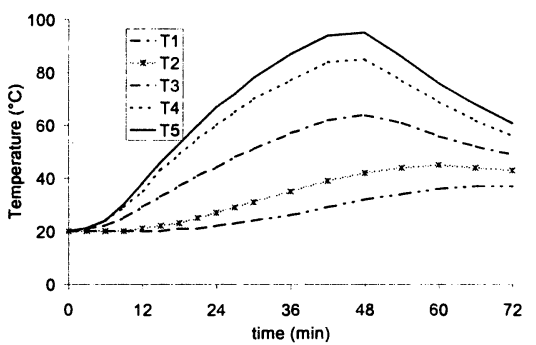

FIGURE 9 : Temperature of the columnsection type 3 at $14 \mathrm{~m}$

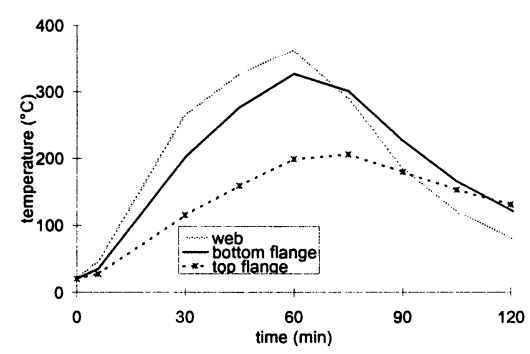

FIGURE 11 : Temperature of section type 5

\section{MECHANICAL BEHAVIOUR}

According to thermal and mechanical actions, the fire behaviour of the steel structure can be determined. 
The fire behaviour of different steel structure elements has been studied taking into account the above calculated temperatures. For the calculations, a 3D thermo-elasto-plastic finite element program "LENAS-MT" [4] has been used (Kaneko, 1990). The mechanical properties of steel elements used are those given by Eurocode 3-part 1.2.

\subsection{Mechanical Actions}

Loading combinations in fire conditions are given by the Eurocode 1 part $2.2+$ French NAD [5] as follows :

$$
\sum_{j \geq 1} \gamma_{G A j} G_{k j}+\Psi_{11} Q_{k 1}+\sum_{i \geq 1} \Psi_{2 i} Q_{k i}+A_{d}
$$

where :

$\mathrm{G}_{\mathbf{k j}}$ : characteristic value of permanent actions

$\mathrm{Q}_{\mathrm{k} 1}$ : characteristic value of one (the main) variable

$\mathrm{Q}_{\mathrm{ki}}$ : characteristic value of the other variable action

$A_{d}$ : design values of accident actions ; in this case fire action (indirect action)

$\gamma_{\mathrm{GAj}}=1:$ partial safety factor for permanent actions in accidental situation

$\Psi_{11}$ : associated coefficient with dominant variable action

$\Psi_{2 i}$ : associated coefficient with non-dominant variable actions

The coefficients $\gamma_{\mathrm{GAj}}, \Psi_{11}$ et $\Psi_{2 \mathrm{i}}$ are given by Eurocode 1 part 2-2, and French NAD.

In the case where the dominant variable action was the service load $Q_{k}$, the load combination has been calculated by the following formula :

$$
\sum_{j \geq 1} G_{k j}+0.7 Q_{k}
$$

In the case where the dominant variable action was the snow load $\mathrm{Q}_{\mathrm{ki}}$, the load combination has been calculated by the following formula :

$$
\sum_{j \geq 1} G_{k j}+0.6 Q_{k}+\sum_{i \geq 1} 0.2 Q_{k i}
$$

For these load combinations the total load on the principal structural elements studied are as follows :

- for the principal truss : $12590 \mathrm{KN}$

- for the secondary truss : $2420 \mathrm{KN}$

- for the column, type $3: 476 \mathrm{KN}$

- for the column, type $4: 492 \mathrm{KN}$

- for the ceiling joist, type $5: 1206 \mathrm{KN}$ 
The internal columns are studied with the principal truss loaded.

\subsection{Results of Calculations}

In conditions of natural fire scenarios "a" and "b", the following are given for the studied steel structures :

- time-displacement curves of some characteristics nodes

- initial and deformed structure at the time of the largest displacement

More details about the fire behaviour of the structure are given in reference [7].

\section{- Principal truss}

The most dangerous fire situation for the principal truss has been given by scenario "a", see 3.1.1. In that case only the lower member of the truss is heated. Two cases have been studied.

Case $1(\mathrm{C} 1)$ : it has been supposed that the lower member is heated along its entire length Case 2 (C2) : it has been supposed that only the part A (figure 5.2) of the lower member is heated.

The time temperature curves attributed to this member are given by figure 6 . The other elements of the truss, being situated in the level 4, are separated from the fire by the concrete floor. Since the hot layer of gases is concentrated in the upper level of waiting hall, we have considered that the heads of the columns have been heated also. The truss is pin-jointed to the columns. The column feet are hinged at their bases. The modelled structure is shown by figure 12.

The figures 12 and 13 show the initial modelled truss structure and its deformed shape after 60 minutes of fire exposure, for the case 1 and case 2 respectively. The figure 15 shows the vertical time-displacement evolution of the node 107 (the largest vertical displacement), for the two cases. In the two cases the maximal vertical displacement is the same, $47 \mathrm{~mm}$.

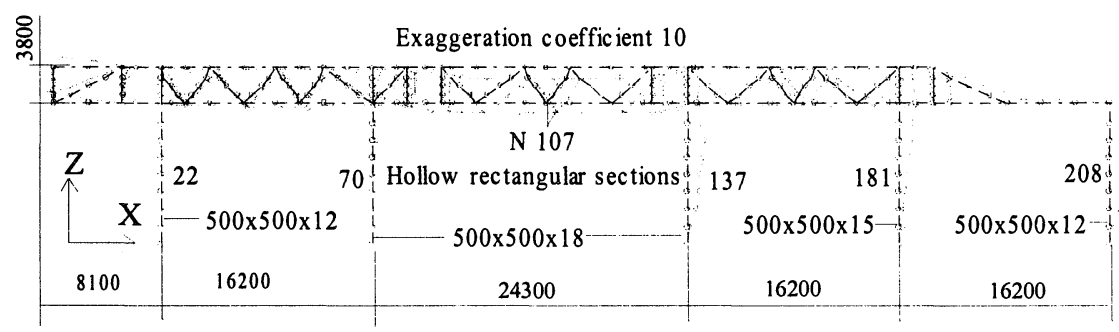

FIGURE 12 : Initial and deformed principal truss structure after 60 minutes of fire exposure 


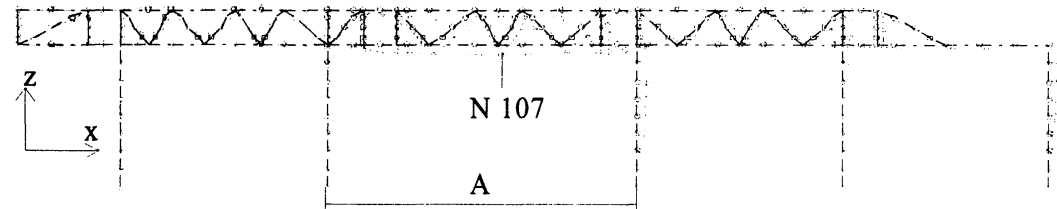

FIGURE 13 : Initial and deformed principal truss structure after 60 minutes of fire exposure, when only the part $\mathrm{A}$ of the lower member is heated

\section{- Secondary truss}

For this truss, the fire scenario "a" was the also most critical. As for the principal truss only the lower member has been heated. The time temperature curves attributed to this member are given by figure 6 .

The figure 14 shows the initial modelled truss structure and its deformed shape after 60 minutes of fire exposure. The figure 16 shows the vertical time-displacement evolution of the node 56 (the largest vertical displacements).

\section{Exaggeration coefficient 10}

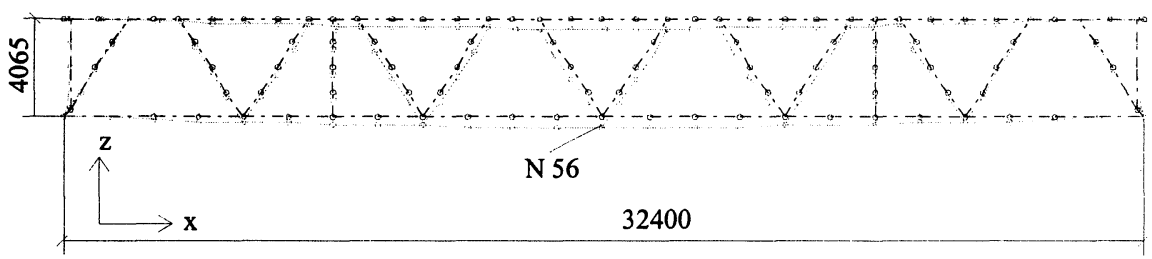

FIGURE 14: Initial and deformed secondary truss structure after 60 minutes of fire exposure

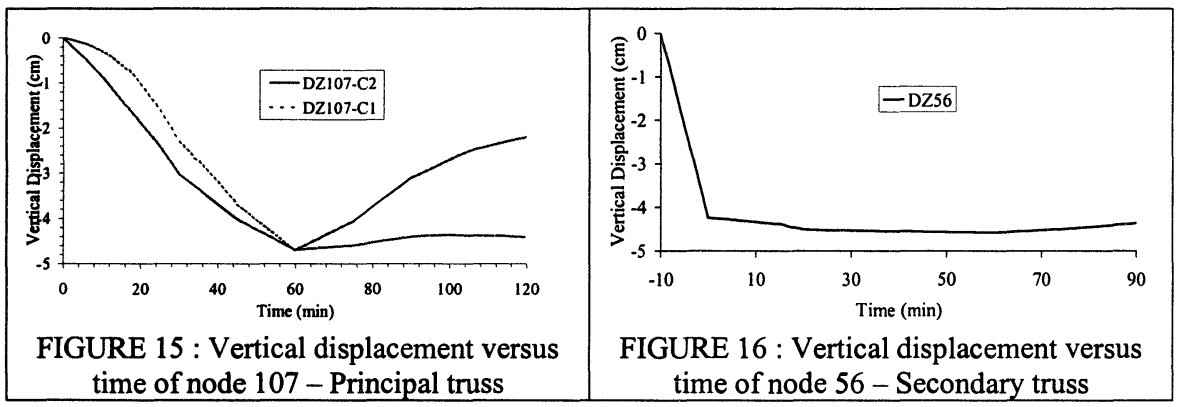

\section{- Internal columns - Type section 2}

The most critical fire for the columns is described by scenario "b", see 4.1.1. This localised fire has been applied on each column separately. The fire behaviour of these columns has been studied with the steel structural model for the loaded principal truss, see figure 5.1. The heating of the lower member of the truss near the head of column has been calculated taking into account the scenario "b". Five calculations have carried out, corresponding to heating of 
only one column at a time. When the columns with a wall thickness of 15 and $18 \mathrm{~mm}$ have been heated the collapse of the structure occurs. The critical temperature for these columns are as follows :

- for the column with section dimensions $500 \times 500 \times 15: \theta_{\mathrm{cr}}=544^{\circ} \mathrm{C}$

- for the column with section dimensions $500 \times 500 \times 18: \theta_{\mathrm{cr}}=515^{\circ} \mathrm{C}$

The heating temperature of these columns has been given in figure 4.5.

The figure 17 shows the horizontal displacement of the node 181 . The collapse of the column occurs after 20 minutes.

\section{- Facade column - Type section 3 - Rectangular hollow section 360x360x12 mm}

This column is situated in the corner of the building. Two sides of the cross section are heated. The mechanical fire behaviour has been studied by the modelling of this column as a separate element. The highest and the lowest temperatures affected to this column are given by figures 8 and 9. The figure 18 shows the horizontal displacement of the node corresponding to the mid-height of the column. The collapse of this column occurs after 38 minutes of fire exposure. The critical temperature of this column is $610^{\circ} \mathrm{C}$.

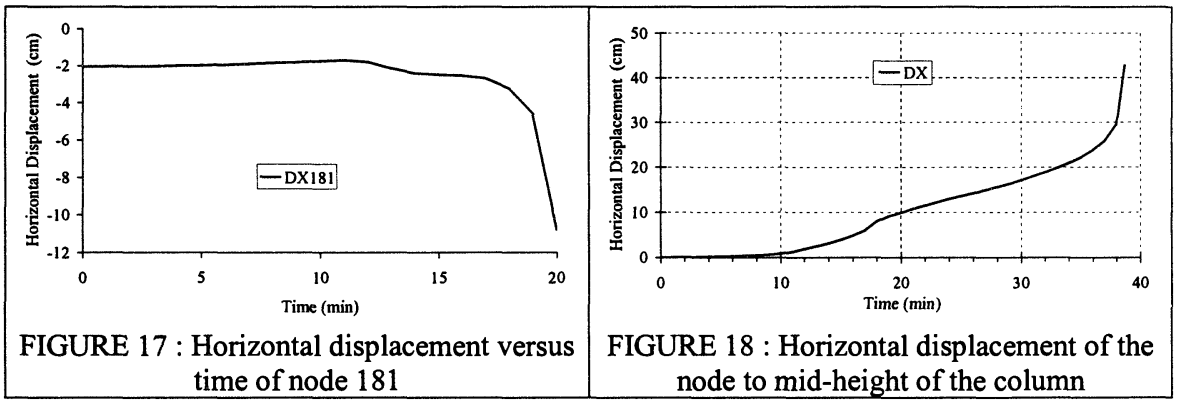

\section{- Facade column - Type section 4 - welded plate girder cross section 500x15-500x8- $500 \times 15$}

This column is heated only on one side. As in the case of corner columns the fire behaviour has been studied by the modelling of this column as a separate element. The fire stability of this column has been verified. The maximum horizontal displacement at mid-height of the column was $105 \mathrm{~mm}$.

\section{- Type section 5 : - Ceiling joist}

The two extremities of ceiling joist are pin-jointed. Only the most heated ceiling joist, under the fire scenario "a", has been presented here. The temperatures of the most heated cross section of this element are given in figure 11 . The require fire stability of this ceiling joist has been verified. The maximum vertical displacement at mid-height of the span was $480 \mathrm{~mm}$.

\section{CONCLUSION}

By using the natural fire safety concept with advanced calculation models for assessing the mechanical behaviour of a large steel building, it was possible to calculate the more precise 
requirements for improving the intrinsic fire resistance of the loadbearing steel elements. In this respect it was possible to demonstrate that, even without any additional fire protection material, the required stability of the beams and trusses is maintained for the whole duration of the expected fire scenarios.

This is not the case when the same analysis is carried out using the conventional ISO-fire. This example of fire in a compartment of large volume is one illustration of the limits of prescriptive rules based on a fully developed ISO fire.

However, this example chosen also illustrates the limit of the use of simple calculation models for assessing the fire resistance of loadbearing elements ; they are mainly valid when these elements are fully engulfed in fire or they have small thermal gradient. When trusses have elements with very different temperatures, advanced calculation models are needed.

With regards to the mechanical behaviour of the steel structure studied the results of this study show that :

- the required fire stability is verified, for each type of fire, for the principal trusses, the secondary trusses, the ceiling joists, the internal rectangular hollow section columns with dimensions $500 \times 500 \times 12$ as well as the facade welded plate girder columns with dimensions $500 \times 15-500 \times 8-500 \times 15$.

- the required fire stability was not verified for the internal rectangular hollow section columns with dimensions $500 \times 500 \times 15$ and $500 \times 500 \times 18$ as well as facade rectangular hollow section columns $360 \times 360 \times 12$. For these columns insulation is needed. To achieve the required fire stability of these elements, suitable thickness of insulation products has been determined as a function of the determined critical temperatures.

\section{REFERENCE}

[1] Sécurité contre l'incendie dans les établissements recevant du public (E.R.P.) Brochure 1540 - Journal Officiel

[2] D. JOYEUX - Vérification du comportement au feu de la structure métallique du plateforme du niveau 4 dans l'hypothèse d'un incendie dans la salle des pas perdus - phase 1 : Proposition des Scénarios d'incendie - INC - 98/50b - DJ/IM - 1998

[3] U. WICKSTRÖM, E. STERNER - TASEF , Temperature Analysis of Structures Exposed to Fire - Fire Technology SP report (1990)

[4] XP ENV 1993-1-2 Eurocode 3 "Calcul des structures en acier" et Document d'Application Nationale - Partie 1-2 : Règles générales calcul du comportement au feu - Décembre 1997.

[5] H. KANEKO - Etude par la méthode des éléments finis en comportement mécanique d'éléments plaques en acier soumis à l'incendie - Revue CM, $\mathrm{n}^{\circ} 1$ (1990)

[6] XP ENV 1991-2-2 : Eurocode 1 "Base de calcul et actions sur les structures" et Document d'Application Nationale - Partie 2-2 : Actions sur les structures exposées au feu - Décembre 1997

[7] D. DHIMA - Vérification du comportement au feu de la structure métallique de la plateforme du niveau 4 dans l'hypothèse d'un incendie dans la salle des pas perdus phase 3 : comportement mécanique", INC - 98/236 - DD/NB - 1998 